\title{
Isolation, Structural Characterization, and Valorization of Pectic Substances from Algerian Argan Tree Leaves (Argania spinosa (L.) Skeels)
}

\author{
Kadda Hachem, ${ }^{1,2}$ Abderrahmane Labani, ${ }^{2}$ and Meriem Kaid-Harche ${ }^{1}$ \\ ${ }^{1}$ Laboratoire des Productions, Valorisations Végétales et Microbiennes, Département de Biotechnologie, \\ Université des Sciences et de la Technologie d'Oran, BP 1505, El Mnaouar, 31000 Oran, Algeria \\ ${ }^{2}$ Département de Biologie, Faculté des Sciences, Université Docteur Moulay Tahar de Saida, BP 138 cité ENNASR, 2000 Saida, Algeria
}

Correspondence should be addressed to Kadda Hachem; kadda46@hotmail.com

Received 27 December 2014; Revised 31 March 2015; Accepted 10 April 2015

Academic Editor: Jin Huang

Copyright (C) 2015 Kadda Hachem et al. This is an open access article distributed under the Creative Commons Attribution License, which permits unrestricted use, distribution, and reproduction in any medium, provided the original work is properly cited.

\begin{abstract}
Pectic polysaccharides were solubilized from Algerian argan tree leaves by sequential extraction with water at $100^{\circ} \mathrm{C}$ (water-soluble pectin; AL-WSP) and EDTA solution at $80^{\circ} \mathrm{C}$ (chelating-soluble pectin; AL-CSP). Both AL-WSP and AL-CSP were rich in arabinose ( $28 \%$ and $74.5 \%$, resp.) and had a high content of uronic acid (38.5\% and $21.5 \%$, resp.). Pectic substances were deesterified and fractionated by anion exchange chromatography, giving five fractions for each extract. Most of the fractions were characterized by methylation analysis and then analyzed by ${ }^{13} \mathrm{C}$ nuclear magnetic resonance spectroscopy. The results showed that AL-WSP consisted of rhamnogalacturonan type I, with arabinan and galactan branching at the O-4 position of the main rhamnose chain, while ALCSP consisted of rhamnogalacturonan type I and a block of homogalacturonan. Antioxidant activities of AL-WSP and AL-CSP were evaluated by electronic spin resonance. The results showed that the antioxidant potential of AL-WSP (8.1\%) and AL-CSP (-1.2\%) was significantly lower than that of vitamin $\mathrm{E}$.
\end{abstract}

\section{Introduction}

Argan tree (Argania spinosa (L.) Skeels), also known as "iron tree," is a woody species belonging to the Sapotaceae family and is endemic to Algeria and Morocco $[1,2]$. Its geographic distribution covers a relatively large area of southwestern Algeria in northern Tindouf, where it is the second most common tree after Acacia raddiana [3]. The argan tree is important both for the local economy and for ecological sustainability. The woodlands protect against soil erosion and desertification owing to their deep-growing roots; they shade different types of crops and help maintain soil fertility in arid zones [4]. Plant cell walls are known to be potential sources of pharmacologically active polysaccharides $[5,6]$. Recently, pectins, a group of anionic polysaccharides that are used in traditional pharmaceutical applications, have attracted a lot of attention and have been subjected to extensive structural study [7]. Pectins are polydisperse macromolecules having high heterogeneity in terms of molecular mass and chemical structure. Their composition is affected by their origin, localization within the plant, and the extraction method used to obtain them. Pectins have a complex structure, which in its majority contains blocks of homogalacturonan (known as "smooth regions") and rhamnogalacturonan (known as "smooth regions").

Studies on the analysis of polysaccharides isolated from argan tree leaves are limited. Ray et al. conducted a study on hemicelluloses isolated from leaves of Moroccan argan tree [8]. The objectives of this study were to (1) study pectic substances extracted from leaves of the Algerian argan tree and (2) evaluate the antioxidant activity of these substances against the stable 2,2-diphenyl-1-picrylhydrazyl (DPPH) radical by using electronic spin resonance (ESR). To the best of our knowledge, this is the first report on pectic substances isolated from the leaves of the Algerian argan tree.

\section{Experimental}

2.1. Plant Material. Argan tree leaves used in this study were collected in June 2007 from Tindouf Province in southwest 


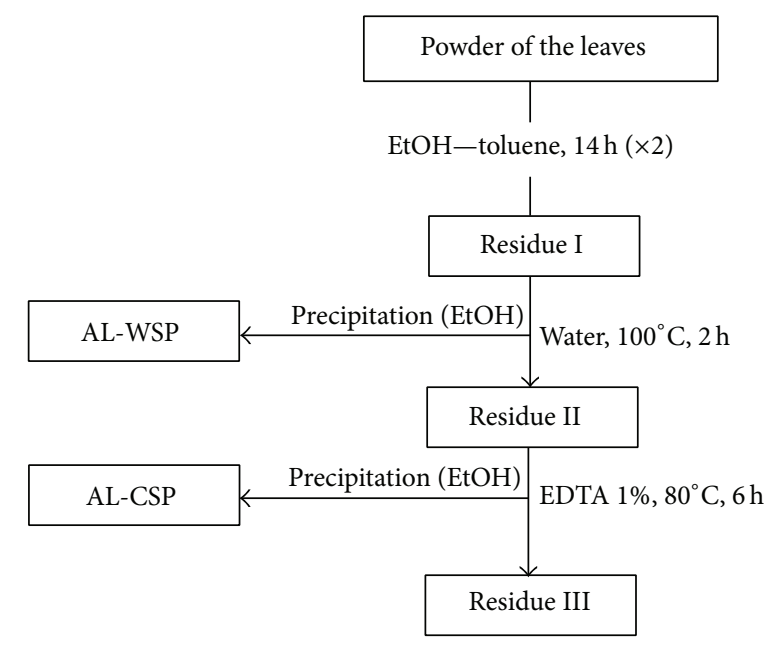

FIGURE 1: Schematic representation of water-soluble (AL-WSP) and chelating soluble (AL-CSP) pectins.

Algeria. After collection, leaves were dried in a ventilated oven $\left(40^{\circ} \mathrm{C}\right)$, ground (particle size $<200 \mu \mathrm{m}$ ), and stored in desiccators at room temperature.

2.2. Cell Wall Preparation. Fifty grams of milled powder was subjected to two successive extractions with 50:50 ethanol-toluene solution at room temperature for $14 \mathrm{~h}$. The supernatant was discarded to remove debris, cytoplasmic organelles, and starch granules. The residue was filtered through a blotting cloth and mixed with ethanol $80 \%$ by continuous stirring for $2 \mathrm{~h}$ to remove any traces of toluene. Then, the residue was washed three times with distilled water and acetone solution, dried in a ventilated oven at $60^{\circ} \mathrm{C}$, and weighed [9].

2.3. Cell Wall Fractionation. Each dried residue was subjected to extraction with ethanol $80 \%$ at $90^{\circ} \mathrm{C}$ for $20 \mathrm{~min}$. The residue was dissolved in distilled water, and the supernatant was recovered by centrifugation. The insoluble material was washed twice with distilled water at $100^{\circ} \mathrm{C}$ for $2 \mathrm{~h}$ to obtain water-soluble pectin (AL-WSP). The remaining residue was treated with $1 \%$ ethylenediaminetetraacetic acid (EDTA) solution at $80^{\circ} \mathrm{C}$ for $6 \mathrm{~h}$ to obtain chelating soluble pectin (AL-CSP). All extracts were filtered through a porous glass frit (Porosity 3 ) and transferred to presoaked dialysis tubing (Spectra/Por; molecular weight cutoff 6,000-8,000 Da). Then it was precipitated with ethanol solution (3 volumes), centrifuged, and finally lyophilized (Figure 1) [10, 11].

\subsection{Analytical Methods}

2.4.1. Gas Chromatography. The composition of neutral monosaccharides was determined from their alditol acetates on a Hewlett-Packard 5890A gas chromatograph (HewlettPackard, Palo Alto, CA, USA), equipped with a polarfused silica capillary column $(30 \mathrm{~m} \times 0.53 \mathrm{~mm})$ and a flame ionization detector (FID) coupled to a Hewlett-Packard 3395 integrator. Column temperature was held at $195^{\circ} \mathrm{C}$ for
$4 \mathrm{~min}$ and ramped at $2.5^{\circ} \mathrm{C} \cdot \mathrm{min}^{-1}$ to $225^{\circ} \mathrm{C}$ and held for 3 min with a constant flow of $4 \mathrm{~mL} \cdot \mathrm{min}^{-1}$ nitrogen carrier gas. The injector and detector temperature were $260^{\circ} \mathrm{C}$ and $280^{\circ} \mathrm{C}$, respectively. Quantification of monosaccharides was conducted using myoinositol as an internal standard against a mixed standard solution of monosaccharides (rhamnose, fucose, xylose, arabinose, mannose, galactose, and glucose) [12].

2.4.2. Colorimetric Method. The content of uronic acid was estimated using the assay of Blumenkrantz and Hansen [13]. The absorbance was read at $520 \mathrm{~nm}$ on a Beckman DU 640 spectrophotometer (Beckman Coulter, Corona, CA, USA).

2.4.3. Ion Exchange Chromatography. Fractionation of pectin was performed by ion exchange chromatography. A $400 \mathrm{mg}$ pectin sample was deesterified using $0.1 \mathrm{M}$ sodium hydroxide solution overnight at $4^{\circ} \mathrm{C}$ under nitrogen. The solution was neutralized with $1 \mathrm{M}$ ( $\mathrm{pH}$ 5.0) hydrochloric acid to obtain the acid form of pectin. Extract was dissolved in approximately $100 \mathrm{~mL}$ of $0.05 \mathrm{M}$ phosphate buffer ( $\mathrm{pH} 6.3$ ) and applied to a DEAE-Trisacryl M column $(2 \times 20 \mathrm{~cm})$. Fractions were eluted at a constant flow of $30 \mathrm{~mL} \cdot \mathrm{h}^{-1}$ with $300 \mathrm{~mL}$ of $0.05 \mathrm{M}$ phosphate buffer and then eluted three more times with $300 \mathrm{~mL}$ of $0.05 \mathrm{M}$ phosphate buffer containing $0.25 \mathrm{M}, 0.5 \mathrm{M}$, and $1 \mathrm{M}$ sodium chloride, respectively. Five fractions were collected for each extract, dialyzed against distilled water, and lyophilized. DEAE-Trisacryl M column was regenerated with $0.5 \mathrm{M}$ sodium hydroxide solution (Figure 2).

2.4.4. Methylation Analysis. Polysaccharides were methylated using sodium hydroxide and methyl iodide in dry dimethyl sulfoxide, according to the method described by Hakomori [14]. Permethylated polysaccharides were hydrolyzed with $2 \mathrm{~N}$ trifluoroacetic acid at $100^{\circ} \mathrm{C}$ for $3 \mathrm{~h}$. Subsequently, they were converted into their corresponding alditol acetates by successive treatments with sodium borohydride and were acetylated with acetic anhydride in the presence of pyridine that acts as a catalyst.

2.4.5. Mass Spectrometry. Permethylated polysaccharides were characterized by a gas chromatograph (HP-Agilent 6850 ) using a $530 \mu \mathrm{m}$ capillary column (SP 2380). The injector temperature is $260^{\circ} \mathrm{C}$ with a constant flow of $4 \mathrm{~mL} \cdot \mathrm{min}^{-1}$ nitrogen carrier gas. Column temperature was held at $165^{\circ} \mathrm{C}$ for $4 \mathrm{~min}$ and ramped at $2.5^{\circ} \mathrm{C} \cdot \mathrm{min}$ to $225^{\circ} \mathrm{C}$ and held for $3 \mathrm{~min}$. After separation in capillary column, methylated derivatives were analyzed by a mass spectrometer (Agilent 5975C, Agilent technologies Inc., Santa Clara, CA, USA).

2.4.6. Nuclear Magnetic Resonance (NMR) Spectroscopy. Samples of $15 \mathrm{mg}$ were dissolved in $0.5 \mathrm{~mL}$ deuterated water $\left(\mathrm{NMR}{ }^{13} \mathrm{C}\right.$ : $15 \mathrm{mg}$ in $0.5 \mathrm{~mL}$ solvent) and NMR spectra were recorded on a Bruker Avance 400 spectrometer equipped with a quadruple nucleus probe at room temperature or at $60^{\circ} \mathrm{C}$ and a frequency of $100.62 \mathrm{MHz}$ for ${ }^{13} \mathrm{C}$. Chemical shifts $\delta$ were expressed in ppm by frequency. The detected frequency for ${ }^{13} \mathrm{C}$ was referenced against tetramethylsilane. 


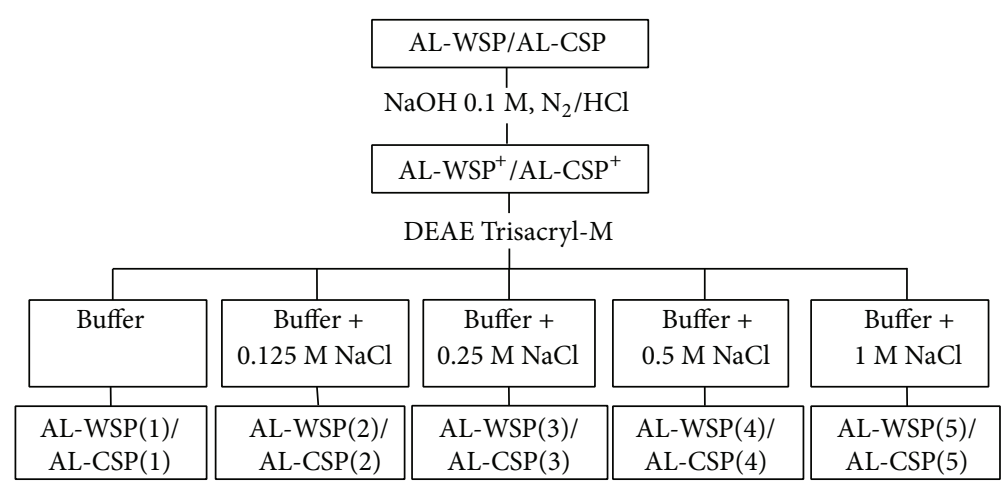

FIGURE 2: Ion exchange chromatography fractionation of water-soluble (AL-WSP) and chelating-soluble (AL-WSP) pectins.

TABLE 1: Monosaccharide yield and composition of water-soluble AL-WSP and chelating-soluble AL-CSP pectins obtained by gas chromatography (GC).

\begin{tabular}{lccccccccc}
\hline \multirow{2}{*}{ Fraction } & \multirow{2}{*}{ Yield $^{\mathrm{a}}$} & \multirow{2}{*}{$\mathrm{UA}^{\mathrm{b}}$} & Rha & Fuc & Ara & Xyl & Man & Gal & Glc \\
& & & 38.5 & 9 & - & 28 & 1 & 0.5 & 11 \\
AL-WSP & 6.5 & 21.5 & 6 & 4.5 & 74.5 & 1.5 & - & 6.5 \\
AL-CSP & 7 & & & & & & 7 \\
\hline
\end{tabular}

${ }^{a}$ Expressed as \% of $15 \mathrm{~g}$ starting leaf powder (dry weight); ${ }^{b}$ expressed as relative weight percentages; ${ }^{c}$ percentage of peak area relative to total peak areas, determined by GC; UA: uronic acid; Rha: rhamnose; Ara: arabinose; Xyl: xylose; Glc: glucose; Gal: galactose; Man: mannose; Fuc: fucose; CSP: chelatingsoluble pectin; WSP: water-soluble pectin; AL: argan tree leaves.

2.4.7. Antioxidant Activity. Antioxidant activity was determined by electron spin resonance (ESR) on a Bruker ESP 300 E spectrometer. Different pectin extracts were evaluated for their DPPH radical scavenging activity [15]. Tested compounds were dissolved in water at different concentrations and scattered for $10 \mathrm{~min}$ in an ultrasonic bath. Radical scavenging activity was evaluated after mixing $50 \mu \mathrm{L}$ of 5 $\times 10^{-4} \mathrm{M} \mathrm{DPPH}$ in ethanol with $50 \mu \mathrm{L}$ of pectin extract solution. ESR spectra were recorded $5 \mathrm{~min}$ after mixing under the following conditions: $100 \mathrm{kHz}$ modulation frequency, $9.78 \mathrm{GHz}$ microwave frequency, $4 \mathrm{~mW}$ microwave power, 1.97 modulation amplitude, and $10.24 \mathrm{~ms}$ time constant. Inhibition was calculated as follows:

$$
\text { Inhibition }=\frac{[\text { ref }- \text { compound }]}{[\text { ref }- \text { bg }]} \text {, }
$$

where ref and compound are the values of the double integrals of ESR spectra of the reference (DPPH + water) and the tested solution (DPPH + pectin extracts in water), respectively; bg represents the background signal (water). Obtained data were the average of three independent measurements. Inhibition of $50 \% \mathrm{DPPH}$ scavenging was calculated from inhibition versus concentration curves.

\section{Results and Discussion}

3.1. Yield and Composition of Monosaccharides. Monosaccharide extraction yield and composition of different polysaccharide fractions, determined by GC as alditol acetates, are presented in Table 1. These results revealed that the two pectin fractions (AL-CSP and AL-CSP) had a similar weight and their extraction yield ranged from $6.5 \%$ to $7 \%$ of the dried material. AL-WSP and AL-CSP were rich in arabinose (28\% and $74.5 \%$, resp.) and uronic acid $(38.5 \%$ and $21.5 \%$, resp.). The high concentration of glucose (50.5\%) in AL-WSP was probably due to contamination with starch from other extraction samples.

The presence of arabinose, galactose, and rhamnose suggested the lack of homogalacturonans in most of the polysaccharide fractions. Thus, the high content of arabinose relative to galactose suggested the presence of side chains of arabinan and/or arabinogalactan. Homogalacturonans ratio ranged from 0.82 to 1 for AL-CSP fractions, which, according to Voragen and Schols $[16,17]$, reveals a predominance of rhamnogalacturonan type I. These results do not exclude the possibility of the presence of rhamnogalacturonan type II as well.

3.2. Fractionation. The percentages of AL-WSP and ALCSP fractions obtained with different eluting solutions are summarized in Table 2. These results showed that AL-WSP and AL-CSP fractions appear as mixtures and subfractions contain acidic polysaccharides. However, each of them was characterized by the dominance of a single subfraction. Most of the subfractions were eluted with $0.25 \mathrm{M} \mathrm{NaCl}$ with total percentage of AL-WSP(3) and AL-CSP(3) to be $23 \%$ and $16.5 \%$, respectively. A significant amount (17.5\%) of AL-WSP(1) fraction, apparently neutral, was recovered with phosphate buffer that did not contain $\mathrm{NaCl}$.

\subsection{Study of $A L$-WSP and $A L-C S P$}

3.3.1. Content of Monosaccharides. Monosaccharide compositions of AL-WSP(3) and AL-CSP(3) are presented in 
TABLE 2: Mass yield of water-soluble AL-WSP and chelating-soluble AL-CSP pectins obtained by ion exchange chromatography.

\begin{tabular}{lcc}
\hline \multirow{2}{*}{ Elution solution } & \multicolumn{2}{c}{ Fraction $^{\mathrm{a}}$} \\
& AL-WSP & AL-CSP \\
\hline (1) Buffer & 17.5 & 7.5 \\
(2) Buffer $+0.125 \mathrm{M} \mathrm{NaCl}$ & 5 & 6.5 \\
(3) Buffer $+0.25 \mathrm{M} \mathrm{NaCl}$ & 23 & 16.5 \\
(4) Buffer $+0.5 \mathrm{M} \mathrm{NaCl}$ & 10.5 & 13 \\
(5) Buffer $+1 \mathrm{M} \mathrm{NaCl}$ & 3.5 & 6 \\
Total & $\mathbf{5 9 . 5}$ & $\mathbf{4 9 . 3}$ \\
\hline
\end{tabular}

Buffer: phosphate buffer $(0.05 \mathrm{M}$, pH 6.3$)$; ${ }^{\text {a expressed as } \% \text { of } 400 \mathrm{mg} \mathrm{AL}-}$ WSP and AL-CSP; CSP: chelating-soluble pectin; WSP: water-soluble pectin; $\mathrm{AL}$ : argan tree leaves.

Table 3. AL-WSP(3) and AL-CSP(3) were acidic and contained approximately $14 \%$ and $25.5 \%$ uronic acid, respectively. They also had significant amounts of arabinose $(65 \%$ in AL$\mathrm{WSP}(3)$ and $68 \%$ in AL-CSP(3)). The presence of rhamnose and galactose was, on average, $15 \%$ in $\mathrm{AL}-\mathrm{WSP}(3)$ and $12 \%$ in $\mathrm{AL}-\mathrm{CSP}(3)$, suggesting that the chains of arabinan and galactan on the rhamnogalacturonan skeleton are connected.

3.3.2. Methylation Analysis. The results of methylation analysis are summarized in Table 4 . These results showed that AL-WSP(3) and AL-CSP(3) had the same composition, but the relative proportions of sugars were different. AL-WSP(3) consisted of alternating rhamnose $(1 \rightarrow 2)$ units, probably linked with galacturonic acid $(1 \rightarrow 4)$ [18]. Monosaccharide determination by methylation analysis showed equivalent amounts of rhamnose and uronic acid (15.5\% and $14 \%$, resp.). The presence of 3-O-methyl-rhamnose indicated that some rhamnose residues were at O-4 position of the side chains $[19,20]$. These results also indicated that $38 \%$ of rhamnose units were substituted. The side chains contained long arabinan chains (71.5\%) and short galactan chains (9.6\%) [21, 22]; however, longer galactose chains as compared to arabinose side chains were also obtained [23-25]. Analysis revealed the presence of two galactose monomers, 2,3,6-tri-O-methyl-galactitol and 2,3,4,6-tetra$O$-methyl-galactitol, both in the same proportion of $4.8 \%$. We assume that these two galactose units are $(1 \rightarrow 4)$ linked on the same side chain. $62 \%$ of rhamnose units were substituted by galactan chains and the remaining $38 \%$ contained arabinose. Several arabinose monomers were also identified in variable percentages: 2,3,5-O-tri-methylarabinitol (33\%), 2,5-O-di-methyl-arabinitol (5\%), 2,3-di-Omethyl-arabinitol (37\%), 2-O-methyl-arabinitol (3\%), and 3$C$-methyl-arabinitol (6\%). These results showed that $62 \%$ of arabinose monomers were $(1 \rightarrow 5)$ linked on the same side chain. This suggests that the arabinan side chain may be mainly composed of $(1 \rightarrow 5)$ linked arabinose units, which can be substituted at the O-3 and/or O-2 position by other arabinofuranose units and, as a result, arabinan units are (1 $\rightarrow 3$ ) linked to oligoarabinoses $[26,27]$.

AL-CSP(3) and AL-WSP(3) have the same characteristics, but the proportion of $(1 \rightarrow 2)$ linked and O-4 branched rhamnose (3-methyl-rhamnose) is higher in AL-CSP than in

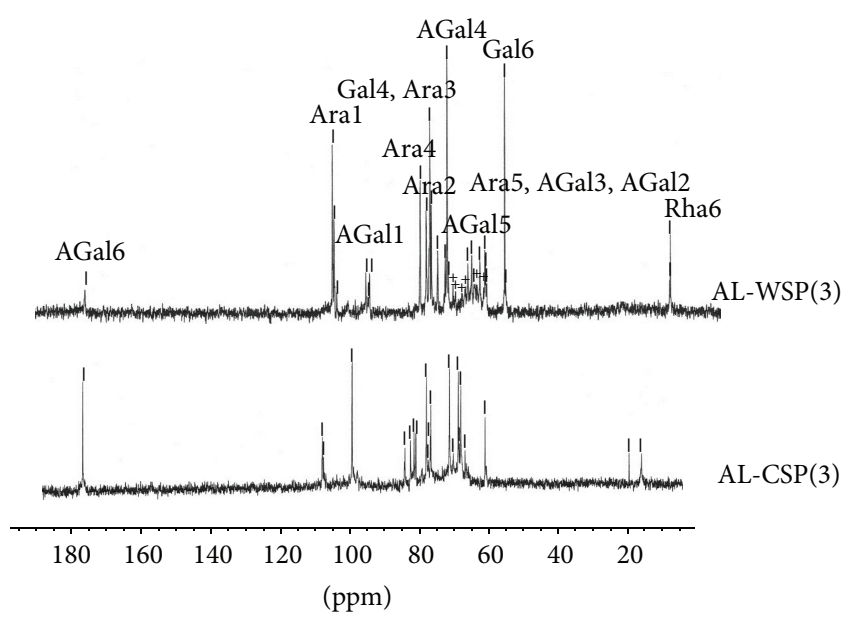

Figure $3:{ }^{13} \mathrm{C}$ spectra of water-soluble (AL-WSP3) and chelatingsoluble (AL-WSP3) pectins.

AL-WSP. Methylation analysis revealed that the proportion of uronic acid (25.5\%) in AL-CSP was higher than that of rhamnose $(14.5 \%)$. These results suggest that AL-CSP(3) has a skeleton that contains both homogalacturonan $[\rightarrow 4)$ galactose-A- $(1 \rightarrow]$ blocks and rhamnogalacturonans $[\rightarrow$ $4)$-galactose-A-(1 $\rightarrow$ 2)-rhamnose- $(1 \rightarrow$ ] blocks [28]. The nature and type of bonds in the side chains are identical to those of AL-WSP(3). Analysis also showed the presence of the same chain in galactan (2 galactose units) and identical arabinan channels with $63 \%$ arabinose bound at $(1 \rightarrow 5)$. These results are in agreement with previous studies in prickly pear seeds [27].

3.3.3. Study by NMR Spectroscopy. Figure 3 shows NMR spectra $\left({ }^{13} \mathrm{C}\right)$ of $\mathrm{AL}-\mathrm{WSP}(3)$ and $\mathrm{AL}-\mathrm{CSP}(3)$. Chemical shift assignment was compared with already published spectral data on the structural characterization of pectins $[25,29,30]$. The detected signals were characteristic of $\alpha-1,5$ arabinan (Ara), $\beta-1,4$ galactan (Gal), $\alpha-1,4$ galacturonan (AGal), and $\alpha-1,2$ rhamnose (Rha). Between $108.17 \mathrm{ppm}$ and $107.76 \mathrm{ppm}$ in the ${ }^{13} \mathrm{C}$ spectrum of $\mathrm{AL}-\mathrm{WSP}(3)$, several characteristic signals of $(1 \rightarrow 5)$ linked arabinose residues were detected. C1 of galacturonic acid and C6 of galactose were identified by $99.6 \mathrm{ppm}$ and $61.7 \mathrm{ppm}$ signals, respectively. The signal at $176.1 \mathrm{ppm}$ was characteristic of carboxyl functional groups of (C6) galacturonic acid units, while the signal at $17.2 \mathrm{ppm}$ was characteristic of (C6) methyl groups of rhamnose residues. These results were in agreement with those obtained by methylation analysis and confirmed that AL-WSP(3) consisted of a main rhamnogalacturonan skeleton. The O-4 position side chains of $(1 \rightarrow 4)$-linked galactan, or $(1 \rightarrow 5)$ linked arabinan, are branched at O-2 and/or O-3 positions.

Spectrum speed of AL-CSP(3) and AL-WSP(3) was similar. The signals at $99.12 \mathrm{ppm}$ and $98.62 \mathrm{ppm}$ were characteristic of the anomeric carbons of $(2 \rightarrow 1)$-linked rhamnose residues and galacturonic acid bound by a $(1 \rightarrow 4)$ link, respectively. The signals at $17.55 \mathrm{ppm}$ and $175.01 \mathrm{ppm}$ were characteristic of methyl rhamnose and the carboxylic 
TABLE 3: Monosaccharide composition of water-soluble AL-WSP(3) and chelating-soluble AL-CSP(3) pectins.

\begin{tabular}{lccccccccc}
\hline \multirow{2}{*}{ Fraction } & \multirow{2}{*}{ Yield $^{\mathrm{a}}$} & \multirow{2}{*}{$\mathrm{UA}^{\mathrm{b}}$} & Rha & Fuc & Ara & Xyl & Man & Gal & Glc \\
\hline AL-WSP(3) & 23 & 14 & 15.5 & 0.5 & 65 & 2.5 & - & 13.5 \\
AL-CSP(3) & 16.5 & 25.5 & 14.5 & 0.5 & 68 & 2.5 & - & 11.5 \\
\hline
\end{tabular}

${ }^{a}$ Expressed as \% of $400 \mathrm{mg}$ AL-WSP(3) and AL-CSP(3) eluted with $0.25 \mathrm{M} \mathrm{NaCl} ;{ }^{b}$ expressed as relative weight percentage; ${ }^{\mathrm{c}}$ percentage of peak area relative to total peak areas, determined by GC; UA: uronic acid; Rha: rhamnose; Ara: arabinose; Xyl: xylose; Glc: glucose; Gal: galactose; Man: mannose; Fuc: fucose; CSP: chelating-soluble pectin; WSP: water-soluble pectin; AL: argan tree leaves.

TABLE 4: Partially methylated alditol acetates ofwater-soluble ALWSP(3) and chelating-soluble AL-CSP(3) pectins obtained by gas chromatography-mass spectrometer (GC-MS).

\begin{tabular}{lcc}
\hline $\begin{array}{l}\text { Partially methylated } \\
\text { alditol acetates }\end{array}$ & AL-WSP(3) & AL-CSP(3) \\
\hline 3,4-Di-methyl-rhamnose & 11.6 & 4.6 \\
3-Methyl-rhamnose & 7.1 & 4.5 \\
Total & $\mathbf{1 8 . 7}$ & $\mathbf{9 . 1}$ \\
\hline 2,3,5-Tri-methyl-arabinose & 23.7 & 28 \\
2,5-Di-methyl-arabinose & 3.6 & 3.3 \\
2,3-Di-methyl-arabinose & 26.7 & 27.4 \\
2-Methyl-arabinose & 12.7 & 24 \\
3-Methyl-arabinose & 4.8 & 3.7 \\
Total & $\mathbf{7 1 . 5}$ & $\mathbf{8 6 . 4}$ \\
\hline 2,3,4,6-Tetra-methyl-galactose & 4.8 & 2.3 \\
2,3,6-Tri-methyl-galactose & 4.8 & 2.1 \\
Total & $\mathbf{9 . 6}$ & $\mathbf{4 . 4}$ \\
\hline
\end{tabular}

${ }^{\text {a }}$ Percentage of peak area of $O$-methylalditol acetates relative to total area, determined by GC-MS.

acid functions of galacturonic residues, respectively. However, multiple signals at $99.60 \mathrm{ppm}, 78.51 \mathrm{ppm}, 71.94 \mathrm{ppm}$, $68.73 \mathrm{ppm}$, and $67.53 \mathrm{ppm}$ were characteristic of $(1 \rightarrow 4)$ linked galacturonic acid units that form blocks of homogalacturonan. These results confirmed that AL-CSP(3) consisted of a main skeleton that has homogalacturonan and rhamnogalacturonan blocks substituted by a galactan and/or arabinan side chain. AL-WSP(3) and AL-CSP(3) can be considered as models of pectin structure synthesized in the cell wall of argan tree leaves. Both fractions have rhamnogalacturonan type I structures, while AL-CSP(3) also has homogalacturonan type structures.

The presence of arabinose and galactose in AL-WSP(3) and AL-CSP(3) that was detected by NMR and methylation analysis revealed two lateral arabinan and galactan branches that were separate and differed in the length of strings (arabinose stings were longer than those of galactose). The structure of rhamnogalacturonan type I is the same in ALWSP(3) and AL-CSP(3) with minor variations. These results are in agreement with previous studies in sugar beet pulp [31] and prickly pear peel [27] but differ from those in potato peel [32], potato pulp [33], and soybeans [34] in which rhamnogalacturonan type I structure is variable.

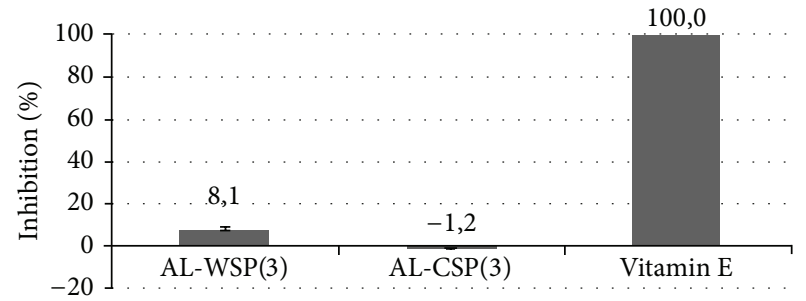

FIgURE 4: Antioxidant activity of water-soluble (AL-WSP3) and chelating-soluble (AL-WSP3) pectins.

3.4. Antioxidant Activity. DPPH scavenging activities of ALWSP(3) and AL-CSP(3) are shown in Figure 4. AL-WSP(3) and AL-CSP(3) showed an antioxidant potential of $8.1 \%$ and $-1.2 \%$, respectively. These percentages were lower than those of vitamin E (100\%). These results were in agreement with previous reports in which 4-O-methyl-glucuronoxylan from Castanea sativa hardwood had insignificant antioxidant activity [35]. It has been shown that the extraction method modifies the structure of polysaccharides by removing acetyl groups or creating new functions and therefore influences their biological properties [36, 37].

\section{Conclusion}

From the foregoing results it can be concluded that ALWSP(3) and AL-CSP(3) can be considered as models of the pectin structure synthesized in the cell wall of Algerian argan tree leaves. These fractions have similar rhamnogalacturonan type I structures with a block in addition to the homogalacturonan type AL-CSP(3) fraction, and with side chains of either arabinan or galactooligosaccharides attached to O-4 of the backbone rhamnose units.

The pectic substances AL-WSP(3) and AL-CSP(3) showed an antioxidant potential lower than those of vitamin E, universally known as a reference of antioxidant compound. The results presented in this primary study need to be conducted by using green chemistry processes, given that the polysaccharide derivatives are considered as potential candidates for natural antioxidant additives in the food and cosmetic industries, because of their environmentally friendly and economic extraction process.

\section{Conflict of Interests}

The authors declare that there is no conflict of interests regarding the publication of this paper. 


\section{Acknowledgments}

The authors would like to thank Professor Vincent Gloaguen, Assistant Director of Laboratory of Chemistry of Natural Substances, EA1069, University of Limoges, France, for his help in ESR analysis and Professor Redouane Boursali, Director of the Research Center on Plant Macromolecules (UPR5301, France), for his help in methylation and NMR analysis. This research was funded by Dr. Moulay Tahar, University of Saida, Algeria.

\section{References}

[1] J. P. Peltier, "Les séries de l'arganeraie steppique dans le Souss (Maroc)," Ecologia Mediterranea, vol. 9, no. 1, pp. 77-88, 1983.

[2] M. Baumer and L. Zeraia, "La plus continentale des stations de l'Arganier en Afriquedu nord," Revue Forestière Française, vol. 51, no. 3, pp. 446-452, 1999.

[3] A. Benkheira, "Larganeraie algérienne, Conservation de la Biodiversité et Gestion Durable des Ressources Naturelles," Une Publication du Projet ALG/G35 9, 2009.

[4] H. Sebaa and M. K. Harche, "Anatomical structure and ultrastructure of the endocarp cell walls of Argania spinosa (L.) Skeels (Sapotaceae)," Micron, vol. 67, pp. 100-106, 2014.

[5] V. Gloaguen and P. Krausz, "Plant polysaccharides: a biologically active class of molecules," SOWF Journal, vol. 130, no. 9, pp. 20-26, 2004.

[6] B. S. Paulsen, "Biologically active polysaccharides as possible lead compounds," Phytochemistry Reviews, vol. 1, no. 3, pp. 379387, 2002.

[7] B. S. Paulsen and H. Barsett, "Bioactive pectic polysaccharides," Advances in Polymer Science, vol. 186, pp. 69-101, 2005.

[8] B. Ray, C. Loutelier-Bourhis, C. Lange, E. Condamine, A. Driouich, and P. Lerouge, "Structural investigation of hemicellulosic polysaccharides from Argania spinosa: characterisation of a novel xyloglucan motif," Carbohydrate Research, vol. 339, no. 2, pp. 201-208, 2004.

[9] M. Harche, M. T. Tollier, B. Monties, and A. M. Catesson, "Caractérisation comparée des constituants (polyosides, lignines et acides phénoliques) des parois cellulaires de trois graminées subdésertiques pérennes: Stipa tenacissima, Lygeum spartum et Aristida pungens," Cellulose Chemistry and Technology, vol. 25, no. 1-2, pp. 11-17, 1991.

[10] D. T. A. Lamport, "Cell wall metabolism," Annual Review of Plant Physiology, vol. 21, no. 1, pp. 235-270, 1970.

[11] J. F. Thibault, "Les substances pectiques," in Les polymères végétaux: Polymères pariétaux et alimentaires non azotés, B. Monties, Ed., pp. 232-251, Gauthier Villars, Paris, France, 1980.

[12] R. R. Selvendran, J. F. March, and S. G. Ring, "Determination of aldoses and uronic acid content of vegetable fiber," Analytical Biochemistry, vol. 96, no. 2, pp. 282-292, 1979.

[13] N. Blumenkrantz and G. A. Hansen, "New method for quantitative determination of uronic acids," Analytical Biochemistry, vol. 54, no. 2, pp. 484-489, 1973.

[14] S.-I. Hakomori, "A rapid permethylation of glycolipid, and polysaccharide catalyzed by methylsulfinyl carbanion in dimethyl sulfoxide," Journal of Biochemistry, vol. 55, no. 2, pp. 205-208, 1964.

[15] C.-A. Calliste, P. Trouillas, D.-P. Allais, and J.-L. Duroux, "Castanea sativa Mill. Leaves as new sources of natural antioxidant: an electronic spin resonance study," Journal of Agricultural and Food Chemistry, vol. 53, no. 2, pp. 282-288, 2005.

[16] A. G. J. Voragen and H. A. Schols, Pectins and Pectinases, Elsevier, 1996.

[17] S. Aboughe-Angone, E. Nguema-Ona, P. Ghosh et al., "Cell wall carbohydrates from fruit pulp of Argania spinosa: structural analysis of pectin and xyloglucan polysaccharides," Carbohydrate Research, vol. 343, no. 1, pp. 67-72, 2008.

[18] J. M. Lau, M. McNeil, A. G. Darvill, and P. Albersheim, "Structure of the backbone of rhamnogalacturonan I, a pectic polysaccharide in the primary cell walls of plants," Carbohydrate Research, vol. 137, pp. 111-125, 1985.

[19] A. G. J. Voragen, W. Pilnik, J. F. Thibault, M. A. V. Axelos, and C. M. G. C. Renard, "Pectins," in Food Polysaccharides and Their Applications, pp. 287-339, Marcel Dekker, New York, NY, USA, 1995.

[20] B. L. Ridley, M. A. O’Neill, and D. Mohnen, "Pectins: structure, biosynthesis, and oligogalacturonide-related signaling," Phytochemistry, vol. 57, no. 6, pp. 929-967, 2001.

[21] J. M. Ros, H. A. Schols, and A. G. J. Voragen, "Lemon albedo cell walls contain distinct populations of pectic hairy regions," Carbohydrate Polymers, vol. 37, no. 2, pp. 159-166, 1998.

[22] Y. Habibi, A. Heyraud, M. Mahrouz, and M. R. Vignon, "Structural features of pectic polysaccharides from the skin of Opuntia ficus-indica prickly pear fruits," Carbohydrate Research, vol. 339, no. 6, pp. 1119-1127, 2004.

[23] B. M. Yapo, C. Robert, I. Etienne, B. Wathelet, and M. Paquot, "Effect of extraction conditions on the yield, purity and surface properties of sugar beet pulp pectin extracts," Food Chemistry, vol. 100, no. 4, pp. 1356-1364, 2007.

[24] E. M. O'Donoghue and S. D. Somerfield, "Biochemical and rheological properties of gelling pectic isolates from buttercup squash fruit," Food Hydrocolloids, vol. 22, no. 7, pp. 1326-1336, 2008.

[25] L. C. Vriesmann and C. L. de Oliveira Petkowicz, "Polysaccharides from the pulp of cupuassu (Theobroma grandiflorum): structural characterization of a pectic fraction," Carbohydrate Polymers, vol. 77, no. 1, pp. 72-79, 2009.

[26] S. M. Cardoso, A. M. S. Silva, and M. A. Coimbra, "Structural characterisation of the olive pomace pectic polysaccharide arabinan side chains," Carbohydrate Research, vol. 337, no. 10, pp. 917-924, 2002.

[27] Y. Habibi, M. Mahrouz, and M. R. Vignon, "Arabinan-rich polysaccharides isolated and characterized from the endosperm of the seed of Opuntia ficus-indica prickly pear fruits," Carbohydrate Polymers, vol. 60, no. 3, pp. 319-329, 2005.

[28] C. M. G. C. Renard, M.-J. Crépeau, and J.-F. Thibault, "Structure of the repeating units in the rhamnogalacturonic backbone of apple, beet and citrus pectins," Carbohydrate Research, vol. 275, no. 1, pp. 155-165, 1995.

[29] C. Rondeau-Mouro, A. Buléon, and M. Lahaye, "Caractérisation par RMN des biopolymères d'origine végétale, de la molécule à lorganisation supramoléculaire," Comptes Rendus Chimie, vol. 11, no. 4-5, pp. 370-379, 2008.

[30] L. Yu, X. Zhang, S. Li et al., "Rhamnogalacturonan I domains from ginseng pectin," Carbohydrate Polymers, vol. 79, no. 4, pp. 811-817, 2010.

[31] F. Guillon and J. F. Thibault, "Methylation analysis and mild acid hydrolysis of the 'hairy' fragments of sugar-beet pectins," Carbohydrate Research, vol. 190, no. 1, pp. 85-96, 1989. 
[32] P. Ryden and R. R. Selvendran, "Structural features of cell-wall polysaccharides of potato (Solanum tuberosum)," Carbohydrate Research, vol. 195, no. 2, pp. 257-272, 1990.

[33] P. Ryden, I. J. Colquhoun, and R. R. Selvendran, "Investigation of structural features of the pectic polysaccharides of onion by 13C-n.m.r. spectroscopy," Carbohydrate Research, vol. 185, no. 2, pp. 233-237, 1989.

[34] M. M. H. Huisman, C. T. M. Fransen, J. P. Kamerling, J. F. G. Vliegenthart, H. A. Schols, and A. G. J. Voragen, "The CDTAsoluble pectic substances from soybean meal are composed of rhamnogalacturonan and xylogalacturonan but not homogalacturonan," Biopolymers, vol. 58, no. 3, pp. 279-294, 2001.

[35] E. Renault, A. Barbat-Rogeon, V. Chaleix, C. Calliste, C. Colas, and V. Gloaguen, "Partial structural characterization and antioxidant activity of a phenolic-xylan from Castanea sativa hardwood," International Journal of Biological Macromolecules, vol. 70, pp. 373-380, 2014.

[36] A. Teleman, J. Lundqvist, F. Tjerneld, H. Stålbrand, and O. Dahlman, "Characterization of acetylated 4-O-methylglucuronoxylan isolated from aspen employing ${ }^{1} \mathrm{H}$ and ${ }^{13} \mathrm{C}$ NMR spectroscopy," Carbohydrate Research, vol. 329, no. 4, pp. 807-815, 2000.

[37] M. Gröndahl, A. Teleman, and P. Gatenholm, "Effect of acetylation on the material properties of glucuronoxylan from aspen wood," Carbohydrate Polymers, vol. 52, no. 4, pp. 359-366, 2003. 

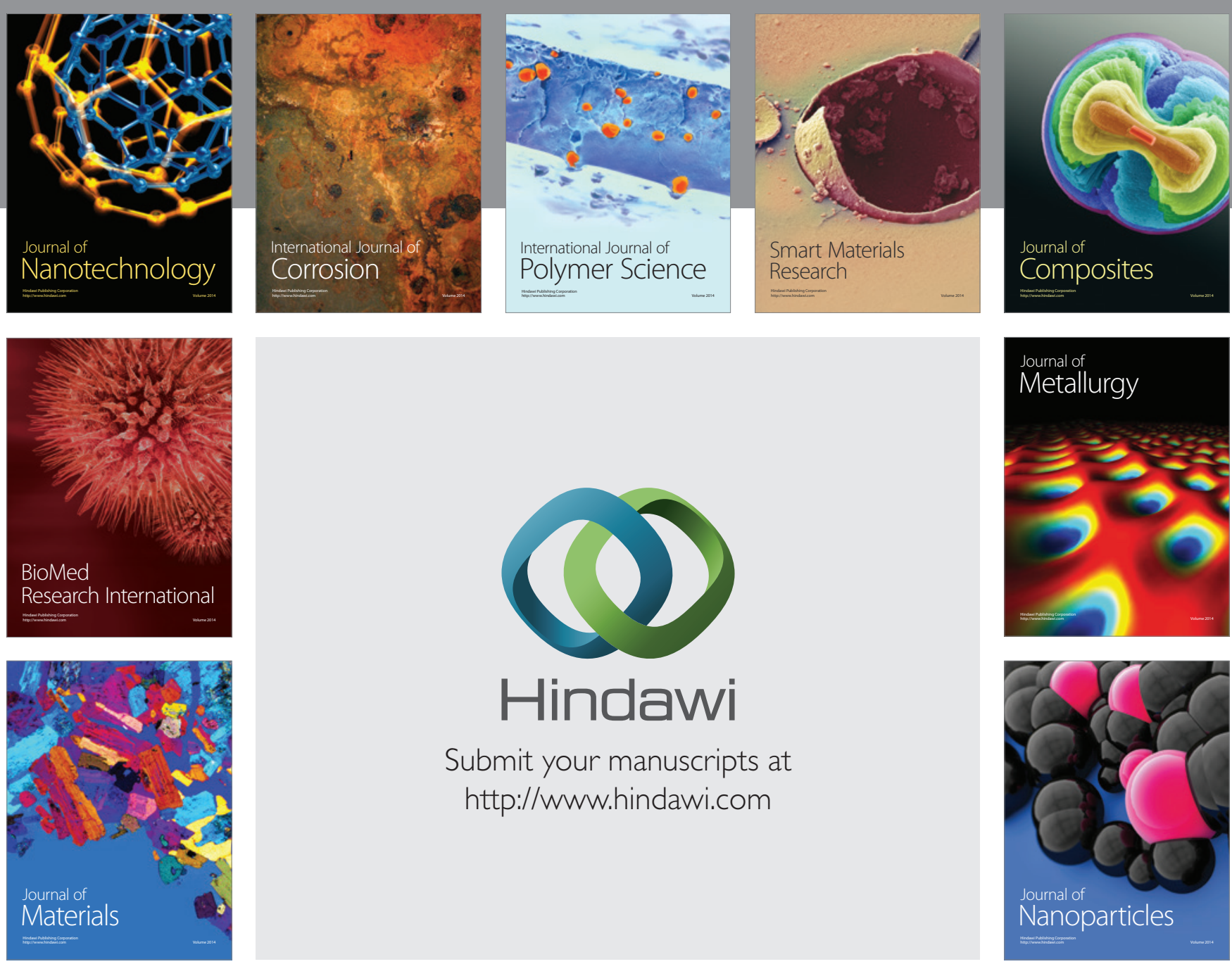

Submit your manuscripts at http://www.hindawi.com
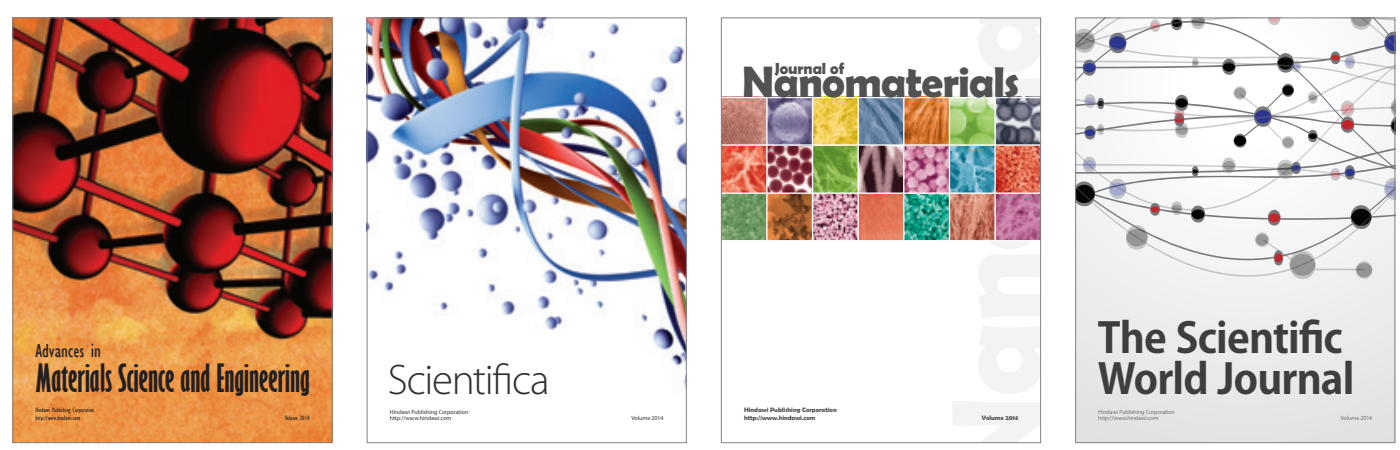

\section{The Scientific World Journal}
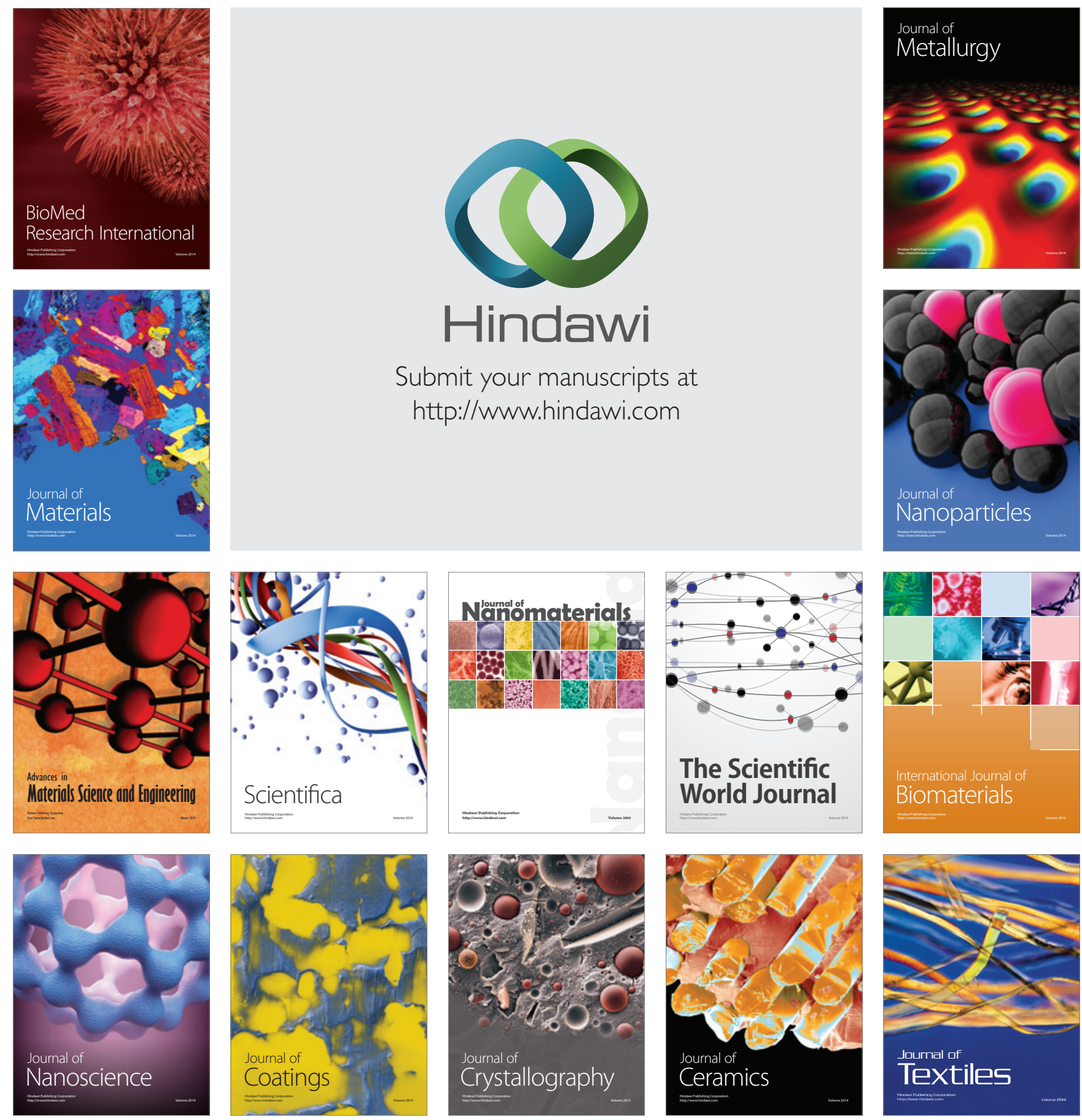